\title{
An International Trade Model with Entrepreneurs and Financial Markets
}

\author{
Bodil O. Hansen ${ }^{1}$, Hans Keiding ${ }^{*}$ \\ ${ }^{1}$ Copenhagen Business School, Copenhagen, Denmark \\ ${ }^{2}$ Institute of Economics, University of Copenhagen, Copenhagen, Denmark \\ Email: boh.eco@cbs.dk, "hans.keiding@econ.ku.dk
}

Received 14 July 2016; accepted 16 August 2016; published 19 August 2016

Copyright $@ 2016$ by authors and Scientific Research Publishing Inc.

This work is licensed under the Creative Commons Attribution International License (CC BY).

http://creativecommons.org/licenses/by/4.0/

(c) (i) Open Access

\begin{abstract}
We consider a two-period model of a three-country world with free trade in finished products and some factor mobility, where production is subject to uncertainty. Enterpreneurs may establish production in other countries but can obtain financing only in the country of origin. In this model, integrating production across countries, in particular integrating economically strong and weak partners, may give rise to a welfare loss, showing that traditional views on efficiency of international trade must be reconsidered when risk and uncertainty are taken into account.
\end{abstract}

\section{Keywords}

International Trade, Entrepreneurs, Pareto Inferior Trade, Regional Integration

\section{Introduction}

In recent years, economic integration has been a main theme of both research and policy, and new forms of integrating of countries into closer economic cooperation are being negotiated in many different parts of the world. While initially economic integration was largely a question of abolishing or diminishing tariffs within the cooperating family of countries (see the classical contributions of e.g. Viner [1] and Vanek [2]), the ongoing process of trade liberalization has shifted focus to other aspects of economic integration. In particular, the liberalization of international financial markets means that the discussion of economic integration must take this as one of the points of departure. This does not mean, however, that there is nothing left over, and that economic integration increases almost independently of any conscious effort of policy makers. As will be shown in this paper, they are welfare improving and welfare reducing forms of integration, depending on whether business becomes truly international; it is not sufficient that entrepreneurs in one country can open up business in another country as

"Corresponding author. 
easy as at home, responding to the economic environments of each country.

In the paper, we build a model of international trade under uncertainty. In its basic form, this model is wellknown from the textbook literature (see e.g. Gandolfo [3]), however new features are added here, in particular the possibility of entrepreneurs to set up production in other countries. Production in any country may be financed either through that country's own financial market or in the financial market of the country of the entrepreneur. Since the conditions of the financial markets reflect country uncertainty, it matters for the outcome of the integration process whether the partners are equal or unequal. In the latter case, economic integration-in the present restricted sense of allowing free movement of entrepreneurs-may turn out to be disadvantageous for some countries from a welfare point of view.

There is by now a considerable literature on models of international trade under uncertainty; among the earlier contributions should be mentioned the work by Helpman and Razin [4], and a survey of some of the results and how they differ from their classical counterparts is given in Hoff [5]. Many of the well-known results of the standard theory do not hold generally in the context of uncertainty and-in particular-asymmetric information. As shown by Newbery and Stiglitz [6], free trade is not necessarily Pareto better than autarky; a similar conclusion can be found in more recent work by Tille [7]. It is therefore not surprising that also the standard results about the possibility of welfare improving economic integration, as formulated e.g. by Kemp and Wan [8], must be qualified suitably when uncertainty and financial markets are introduced. We stress that although the financial markets in our model are not perfect, since the entrepreneurs of the country cannot turn to foreign countries for financing investment at home, the imperfections of our model are not at variance with what is observed in reality, where full liberalization of capital movements certainly do not preclude that borrowers in any particular country may experience high interest rates or even creditrationing.

We follow the tradition of international trade theory in dealing with a world where two commodities are produced from two inputs, using a technology which is known to everybody. There is a given number of firms or entrepreneurs, but an entrepreneur may choose to produce either of the two commodities, and-if economic integration is possible - to operate the firm in another country; thus the distribution of firms producing one or the other commodity is an equilibrium outcome of the model. The point of this way of introducing entrepreneurship is that the progress expected from economic integration would be that domestic firms get a larger share of world production, rather than that foreign firms establish branches in the country to exploit cheap production factors. It should be noticed that we remain within the framework of non-increasing returns to scale, and the total number of firms remains fixed, only their distribution among industries and countries is determined by the model. Thus our approach is different from that of Markusen and Venables [9] [10], where multinational firms are incorporated in a model of international trade with monopolistic competition. In our model, there is perfect competition throughout, at least given the structural limitations of the financial markets. Also, while the notion of an entrepreneur is important and much used in the paper, the role of the entrepreneur is confined to decisions about opening up production and choosing its size in the countries where this is possible. Other-and potentially more important-roles of the entrepreneur, as those considered e.g. by Rauch and Watson [11], are disregarded.

Throughout the paper, we assume that there is free international trade in commodities, while factors of production cannot be traded between countries; as mentioned above, firms of one country may however operate in another country, at least under suitable regimes of economic integration, thereby achieving results which are similar to moving the factors of production. One may think of this approach as a first step towards inclusion of entrepreneurship into the classical models of international trade; for other recent contributions in this direction, see $\mathrm{Yu}$ [12], $\mathrm{Wu}$ [13]. In the definition of equilibria, we assume that consumers choose savings under assumptions on the (random) yield of bonds which are rational in the sense that they are confirmed by actual performance.

The markets for bonds issued by firms of a given country play an important role, and since the performance of any such market is determined by the outcome of the firms of this country, the repayment rates are expressions of the country risk which is related to with the economic size of the country; since output shocks are independent, the variance of output produced by firms of that country will be smaller, the larger its number of firms, and the lower will be the repayment rate at which the bond will be demanded by the consumers. Thus, country risk is connected with economic size or strength, and an economic integration which allows for operation of one country's firms in another country, while retaining country-specific bond markets, may result in a situation where the smaller country's firms close down while its factors of production are employed in firms belonging to the larger country. This is the case of disadvantageous integration; it does not arise when the participating countries are of comparable size. 
Thus, while in our model—as indeed in most models of international trade—full integration is better than autarky, it is by no means the case that any arrangement which increases the economic integration of the countries will be beneficial the parties. This has been noticed by other authors as well, though in different contexts, and there is by now a considerable literature on the pros and cons of regional economic integration, cf. e.g. Amiti [14], Bond, Syropoulos and Winters [15], Ornelas [16], Wu [13], Abrego, Riezman and Whalley [17].

The paper is organized as follows: In Section 2, we introduce the model, which is a standard simple trade model over two periods and with uncertainty. The uncertainty comes from independent and identically distributed output shocks in the firms, and it affects second period output and consumption as well as the payoff of the bonds used to finance the investment in production factors needed to produce the outcome. In the following section, we consider the special case of constant returns to scale in production; here equilibrium profits are zero, and the workings of the model become more transparent, but on the other hand it fails to illustrate the role of the entrepreneur, which does not then play an essential role. In Section 4, we treat the more general case of non-increasing returns to scale, opening up for nonzero profits as well as a choice of industry by entrepreneurs. Having treated the basic features of the model, we may then turn to what was its purpose, namely the study of economic integration, which is done in Section 5; here we show that in certain cases (namely such where all other, traderelated, effects of integration are netted out) integration between economically strong (in the sense of having many firms) and weak (few firms) countries will have unfavorable effects for the latter, whereas economic integration by more evenly situated countries will be welfare improving for both. Section 6 contains some concluding comments. Proofs of the propositions stated in the text are collected in an appendix to the paper.

\section{The Model}

We consider a model of trade based on the classical Heckscher-Ohlin-Samuelson model with two produced commodities and two productive factors; one may, as usual, think of the factors as capital and labor, whereby the first is internationally mobile while the second cannot be traded between countries. We shall assume that there are three countries, so that we may consider the case where two countries undergo some form of economic integration while leaving the third country outside. The countries are assumed to be identical with respect to producers' and consumers' characteristics but they may differ in size.

We now proceed to the specific details of the model, related to the way that production is carried out, the households, and financial intermediation.

Consumption. Consumers who are not entrepreneurs will be referred to in the sequel as factor owners. To avoid excessive notation (and in accordance with tradition in trade theory), we assume that there is only one factor owner in each country ${ }^{1}$. Consumption takes place only at $t=1$, so the consumer sells the endowment of production factors to the firms at $t=0$ at prices $\left(q_{1},\left(q_{2}^{1}, q_{2}^{2}, q_{3}^{3}\right)\right)$ (the first production factor can be traded internationally, the second cannot) and saves the income using the available financial institutions. At $t=1$, the repayment of the savings is used to buy the two consumption goods at state-dependent prices $\left(p_{1}(s), p_{2}(s)\right)$; free international trade of the output commodities is assumed throughout.

Production is carried out in firms run by consumer-entrepreneurs. There is a given set $N_{k}$ of entrepreneurs in each country $k$, and each entrepreneur $v$ in country $k=k(v)$ can set up exactly one firm, chosen from the a set $H_{k}$ of available pairs $(h, i)$ of combinations of country and industry. We write the choice of entrepreneur $v$ as $(h(v), i(v))$. Entrepreneurs have no initial endowment, so they have to obtain credits for buying input commodities in order to carry out production.

Each commodity $y_{i}, i=1,2$, is produced separately using the two input commoditiesat $t=0$ and yielding output at $t=1$; the technology of a firm $v$ producing commodity $i$ is given by a productionfunction

$$
y_{i}=\tau_{v} f_{i}\left(z_{1 i}, z_{2 i}\right) \text {; }
$$

here $\tau_{v}$ is a random variable taking the values 1 ("success") or 0 ("failure"). The variables $\tau_{v}$ are independent and identically distributed. Notice that the shock pertains to the entrepreneur, not the industry or the country in which production is carried out. We denote by $\pi$ the probability of failure, that is the event $\tau_{v}=0$. The function $f_{i}$ is assumed to be differentiable and to satisfy the boundary condition $\lim _{z \rightarrow 0} f_{i}^{\prime}(z)<\infty$. If the entrepreneur succeeds, then the debt is repaid and the remainder is used for buying consumption goods. In the case of

\footnotetext{
${ }^{1}$ This is not too restrictive in our context of identical consumers, since consumers with identical homogeneous utility functions may be aggregated into a single one, cf. Chipman [18].
} 
failure, the entrepreneur has zero consumption at $t=1$. All entrepreneurs have the same utility function $u$ with $u(0)=0$.

Financial intermediation. In order to link consumer savings with firms' borrowing, we introduce a financial intermediary. We assume that in each country, bonds are issued at a nominal repayment rate $R^{h}$, which depends on country of issue $h$; thus, the bonds financing the production of entrepreneur $v$ can be distinguished only by nationality $k(v)$ of the entrepreneur $v$, not by the individualdebtor ${ }^{2}$. Once issued, the bonds can be traded in all countries.

Since the production shocks give rise to uncertainty, we need to keep track of the states that can obtain. A state s specifies success or failure for each entrepreneur as well as the industry of operation. For later purpose, it is convenient also to take into account the country of operation of each entrepreneur when identifying a state. We denote by $S$ the (finite) set of states and by $\pi(s)$ the probability of the state $s \in S$.

Individual optimality. The factor owner faces the problem of choosing an optimal portfolio of bonds, so that expected utility of the bundles bought using the bond yield is maximal. With given factor prices $\left(q_{1},\left(q_{2}^{1}, q_{2}^{2}, q_{2}^{3}\right)\right)$ and state-dependent prices of consumption goods $\left(p_{1}(s), p_{2}(s)\right), s \in S$, the factor owner in country $h$ must choose a portfolio of bonds, here in the form of a nonnegative vector $\theta^{h}=\left(\theta_{k}^{h}\right)_{k=1}^{3}$ with $\sum_{k=1}^{3} \theta_{k}^{h}=1$ specifing the proportion of savings used for bonds of type $(k, i)$, and (state-dependent) consumption bundles $x^{h}=\left(x_{1}^{h}(s), x_{2}^{h}(s)\right)_{s \in S}$, in such a way as to maximize expected utility, solving the problem

$$
\begin{aligned}
& \max E u_{h}\left(x_{1}^{h}(s), x_{2}^{h}(s)\right) \\
& \text { subject to } p_{1}(s) x_{1}^{h}(s)+p_{2}(s) x_{2}^{h}(s) \leq\left[q_{1} \omega_{1}^{h}+q_{2}^{h} \omega_{2}^{h}\right] \sum_{k=1}^{3} \theta_{k}^{h} \pi(s) R^{k}, s \in S .
\end{aligned}
$$

The entrepreneur $v$ in country $k(v)$ must solve a consumption choice problem similar to (2), and in addition to this, choose the country and industry in which to operate. This means that country and industry $(h, i) \in H_{k}$, inputs $z_{h, i}^{v}=\left(z_{h, i, 1}^{v}, z_{h, i, 2}^{v}\right)$ and consumption bundles $x_{h, i}^{v}=\left(x_{h, i, 1}^{v}(s), x_{h, i, 2}^{v}(s)\right)_{s \in S}$ must solve the problem

$$
\begin{aligned}
& \max _{(h, i) \in H_{k}, z_{h, i}^{v}, x_{h, i}^{v}} \operatorname{E} u\left(x_{h, i}^{v}(s)\right) \\
& \text { subject to } p(s) \cdot x_{h, i}^{v}(s) \leq \max \left\{0, p_{i}(s) f_{i}\left(z_{h, i}^{v}\right)-R^{k}\left(q_{1} z_{h, i, 1}^{v}+q_{2}^{h} z_{h, i, 2}^{v}\right)\right\}, \text { all } s \in S,
\end{aligned}
$$

If the entrepreneurs are bankrupt at $t=1$, their consumption is 0 . Since entrepreneurs differ only in their country of origin, the solution to the problem (3) will be the same for all entrepreneurs $v$ with $k(v)=k$.

We may now proceed to the formulation of conditions for an equilibrium in our model: For this, we need that all factor owners and entrepreneurs achieve their individual optima as specified in (2) and (3), and in addition, supply and demand of goods at $t=1$ should balance for each state $s \in S$,

$$
\sum_{h=1}^{3} x_{i}^{h}(s)+\sum_{v \in N} x_{i}^{v}(s)=\sum_{v \in N: i(v)=i} \tau_{v}(s) f_{i}\left(z^{v}\right), i=1,2,
$$

and finally, for each country $k$ and industry $i$, the factor demand of entrepreneurs in $k$ is constrained by the availability of credit

$$
\sum_{h=1}^{3}\left[q_{1} \omega_{1}^{h}+q_{2}^{h} \omega_{2}^{h}\right] \theta_{k}^{h}=\sum_{v: i(v)=i, k(v)=k} \sum_{h=1}^{3}\left(q_{1} z_{h, i, 1}^{v}+q_{2}^{h} z_{h, i, 2}^{v}\right) .
$$

Defining an equilibrium in this way will work well in examples, but from the formal point of view, there are some fundamental non-convexities involved in the entrepreneurs' choices of country and industry of operation, and we cannot in general be sure that an equilibrium exists. Therefore, we extend it slightly be allowing entrepreneurs to randomize their choice of country and industry. This means that instead of a definite choice of country and industry in which to operate, we assume that entrepreneurs $v$ in country $k$ choose a probability distribution $\mu_{v}$ on a subset $H_{k}$ of allowed country-industry pairs $(h, i)$. The equilibrium conditions are adapted to this situation.

\footnotetext{
${ }^{2}$ This will be the case if the financial intermediaries take the form of coalitions of borrowers, cf. e.g. Leland and Pyle [19], Diamond [20].
} 
Definition 1. An array $\left(\left(x^{h}, \theta^{h}\right)_{h=1}^{3},\left(\mu_{v},\left(z_{h, i}^{v}, x_{h, i}^{v}\right)_{(h, i) \in H_{k(v)}}\right)_{v \in N},(q, p),\left(R^{k}\right)_{k=1}^{3}\right)$ is an equilibrium if the following conditions are fulfilled:

1) for each country $h,\left(x^{h}, \theta^{h}\right)$ solves the problem (2),

2) for each entrepreneur $v$ of country $k=k(v), \mu_{v}$ is a probability on $H_{k}$ such that each $\left(z_{h, i}^{v}, x_{h, i}^{v}\right)$ with $\mu_{v}(h, i)>0$ solves the problem (3),

3) $\sum_{v \in N} \sum_{(h, i) \in H_{k(v)}} \mu_{v}(h, i) z_{h, i, 1}^{v}=\sum_{h=1}^{3} \omega_{1}^{h}, \quad \sum_{v \in N} \sum_{(h, i) \in H_{k(v)}} \mu_{v}(h, i) z_{h, i, 2}^{v}=\omega_{2}^{h}$ for each country $h$, and for each state $s \in S$,

$$
\sum_{h=1}^{3} x_{i}^{h}(s)+\sum_{v \in N} x_{i}^{v}(s)=\sum_{v \in N} \tau_{v}(s) \sum_{(h, i) \in H_{k(v)}} \mu_{v}(h, i) f_{i}\left(z_{h, i}^{v}\right), i=1,2
$$

4) for each country $k$ and industry $i$,

$$
\sum_{h=1}^{3}\left[q_{1} \omega_{1}^{h}+q_{2} \omega_{2}^{h}\right] \theta_{k}^{h}=\sum_{v: k(v)=k} \sum_{(h, i) \in H_{k(v)}} \mu_{v}(h, i)\left(q_{1} z_{h, i, 1}^{v}+q_{2} z_{h, i, 2}^{v}\right)
$$

It can be seen that we have formalized the randomized choice as a possibility of splitting the activities so as to operate at a part-time basis in several countries and industries. The possibility of failure, which is related only to the entrepreneur, remains the same for all the part-time activities.

With our standard assumptions on consumers and technology, equilibria exist:

Proposition 1. Assume that

1) utility functions $u_{h}, h=1,2,3$, and $u$ are continuous, monotonic andquasi-concave,

2) production functions $f_{i}$ are continuous, monotonic, and concave.

3) $\omega_{i}^{h}>0, \quad i=1,2$, for each $h$.

Then there exists an equilibrium.

The proof of this and other propositions are given in the appendixto the paper.

\section{Advantageous and Disadvantageous Integrations}

Having developed the model in the course of the previous sections, we may now put it to the usefor which it was designed,as outlined in the introduction, namely that of economic integration, partial or full. In our modelwith unrestricted free trade inoutput commodities, economic integration must take one of the following forms:

1) integrated factor markets ("unrestricted movement of factors of production"),

2) integrated financial markets (one common bond, and consequently one repayment rate,

3) right of establishing a firm in any of the countries involved.

While the first two aspects of economic integration may suggest themselves from the very logic of this (and other) models of international trade, the third form of economic integration may indeed be much closer to real world phenomena. Indeed, the typical result of closer economic cooperation is that production is moved from countries with high factor prices to low cost countries, while the basic structure of the firm, including its methods of obtaining funds for investments, is retained. In the following, we concentrate on this type of economic integration which is little investigated in the literature and which also produces some rather striking results. Thus, in the following we concentrate on integration of type 3).

Formally, if countries hand $\mathrm{k}$ belong to a group of countries having chosen to integrate their economies, then any firm of country $h$ may choose to operate in country $k$ (and vice versa). Given such a choice, the firm will use the bond market of its country of origin and the factor market in the country of operation.

Economic integration understood as perfect firm mobility makes it possible for a firm to exploit differences in credit availability and in factor price levels: If its home country has a large number of firms, and consequently small variance in output, its firms have access to credit with low rate of repayment. Moving to a country with fewer firms and more expensive credits, it can offer the factor owners of that country better prices than the domestic firms. This will wipe out the domestic firms, so that entrepreneurship and the profits which are derived from it is transferred from the small country to the large one, producing a case of disadvantageous economic integration. 
Example. To show that credit availability matters, we consider an example of a three-country world, where all countries are identical except for their size, so that in a classical setup, there would be no international trade.

The technology is assumed to display constant returns to scale, with production functions (before the random shock)

$$
y_{1}=z_{1}^{\frac{1}{3}} z_{2}^{\frac{2}{3}}, y_{2}=z_{1}^{\frac{2}{3}} z_{2}^{\frac{1}{3}}
$$

The random shock occurs with probability $1 / 3$ in each country and industry. Country 1 has factor endowment $(2,2)$ and 4 entrepreneurs, whereas countries 2 and 3 each have endowment $(1,1)$ and 2 entrepreneurs. We assume that none of the factors can be traded, so that we are in the classical framework of international trade theory.

Consumers and entrepreneurs all have the utility function

$$
u\left(x_{1}, x_{2}\right)=\ln \left(x^{\frac{1}{2}} x^{\frac{1}{2}}+1\right) .
$$

Thus the consumers have homothetic preferences, meaning that they consume the goods in the same proportion independent of the income which they get at $t=1$. Since $u$ is concave, consumers are risk averse.

To simplify the model, we assume that consumers have limited information about the impact of the uncertain production shock, so that they can identify only the uncertainty arising from aggregate supply of goods in the market at $t=1$; at $t=0$ they base their choice on the distribution of repayments: if all $N_{k}$ entrepreneurs of country $k$ are active, and $d_{k}$ of the entrepreneurs i default, bond owners consumers get the repayment

$$
\frac{N_{k}-d_{k}}{N_{k}} R_{k} \text { with probability }\left(\begin{array}{c}
N_{k} \\
d_{k}
\end{array}\right) \pi^{d_{k}}(1-\pi)^{N_{k}-d_{k}}
$$

For our present purpose, what matters is not the exact distribution but the fact that with a fixed nominal repayment rate, consumers will prefer bonds with a less risky repayment, that is bonds issued in countries with the largest $N_{k}$. In order to be competitive, bonds from other countries must be sold at a higher nominal repayment rate. However, with constant returns to scale (and identical factor prices, something which will be satisfied in equilibrium), average profit of the firms must be 0 and the nominal repayment rate therefore the same for all active firms.

Given this comparative advantage of the large country in the credit market, we compare two situations, (a) full integration, where any entrepreneur may set up business in all three countries, formally $H_{k}=\{1,2\} \times\{1,2,3\}$, all $k$, and (b) no integration, where entrepreneurs can operate only in their own country, that is $H_{k}=\{1,2\} \times\{k\}$, all $k$. We begin with the case (a). According to our previous considerations, only entrepreneurs of country 1 will be active, and if all choose the same input-output combination, then each have an output of 1 unit (before shock) of the relevant commodity, so if no shock occurs, aggregate output is $(2,2)$. The probability of no shocks in the four firms is $(2 / 3)^{4}=0.2$ (each firm is hit with probability $1 / 3$, and the shocks are independent). Since there are no defaults, there will be $7=3+4$ active consumers ( 3 factor owners and four entrepreneurs) in the market at $t=1$, and assuming for simplicity equal division of the aggregate supply among the utility (listed in the last column) by inserting $(2 / 7,2 / 7)$ into (6), giving a total of 1.76 . Repeating the computations for all possible aggregate output combinations, we get the results listed in Table 1.

Using the data in third and the fifth column, we find that expected aggregate utility is

$$
0.2 \times 1.76+0.40 \times 1.27+0.1 \times 0+0.2 \times 0.91+0.1 \times 0+0.01 \times 0=1.03 \text {. }
$$

which is an upper bound on aggregate utility in the equilibrium (not the exact value since we have assumed equal division of the aggregate output), and as such it may be used for comparison with the case of no integration.

If entrepreneurs can set up firms only in their own country, they will be the only ones to exploit the factors, so entrepreneurs will be active in this country as well. Consequently, aggregate output, which as before is at most $(2,2)$, is split among 8 instead of 4 entrepreneurs. Repeating the computations in Table 1 for the present case, we get the results in Table 2 (situations with aggregate utility 0 have been omitted).

Now expected average utility is 1.18 , which exceeds that of case (a). In this sense, no integration is better than full integration. The reason that we get this type of result has already been revealed: Due to risk aversion, it is 
Table 1. Full integration: Aggregate output, probabilities, aggregate utility depending on the incidence of shocks.

\begin{tabular}{ccccc}
\hline Commodity 1 & Commodity 2 & Probability & Active consumers & Aggregate utility \\
\hline 2 & 2 & 0.20 & 7 & 1.76 \\
1 & 2 & 0.40 & 6 & 1.27 \\
0 & 2 & 0.10 & 5 & 0.00 \\
1 & 1 & 0.20 & 5 & 0.91 \\
1 & 0 & 0.10 & 4 & 0.00 \\
0 & 0 & 0.01 & 3 & 0.00 \\
\hline
\end{tabular}

Table 2. No integration: Aggregate output, probabilities, aggregate utility depending on the incidence of shocks.

\begin{tabular}{ccccc}
\hline Commodity 1 & Commodity 2 & Probability & Active consumers & Aggregate utility \\
\hline 2 & 2 & 0.04 & 11 & 0.07 \\
1.5 & 1.5 & 0.16 & 9 & 1.39 \\
1 & 1 & 0.09 & 7 & 0.93 \\
0.5 & 0.5 & 0.01 & 5 & 0.48 \\
2 & 1.5 & 0.16 & 10 & 1.60 \\
2 & 1 & 0.12 & 9 & 1.31 \\
2 & 0.5 & 0.04 & 8 & 0.94 \\
1.5 & 1 & 0.23 & 8 & 1.14 \\
1.5 & 0.5 & 0.08 & 7 & 0.82 \\
1 & 0.5 & 0.06 & 6 & 0.67 \\
\hline
\end{tabular}

better that aggregate production is carried out in 8 firms than in 4 firms. Thus, the inclusion of uncertainty and risk aversion into the models of international trade means that the traditional results must be properly reconsidered; integrating the economics may not always improve efficiency (in the broad sense including consumer welfare).Strictly speaking, what we have compared was not equilibrium allocations but rather allocations obtained after a suitable redistribution, but a closer look at the tables reveals that what matters for the results are the cases of only few shocks, and here the equilibrium allocations will be close to egalitarian.

The above intuition is confirmed by the following proposition, which treats the case where all countries have been integrated into a single economic area (keeping however the structure of financial intermediation based on national bond emission).

Proposition 2. Assume constant returns to scale in production and $\left|N_{1}\right|>\left|N_{2}\right|=\left|N_{3}\right|$, and let $H_{k}=\{(h, i) \mid h=1,2,3, i=1,2\}, \quad k=1,2,3$ (full integration). For each $\varepsilon>0$, there is $\left|N_{k}\right|>\bar{N}$ such that for all $\left|N_{k}\right|>\bar{N}$, if $\left(\left(\hat{x}^{h}, \hat{\theta}^{h}\right)_{h=1}^{3},\left(\hat{\mu}_{v},\left(\hat{z}_{h, i}^{v}, \hat{x}_{h, i}^{v}\right)_{(h, i) \in H_{k(v)}}\right)_{v \in N},(\hat{q}, \hat{p}),\left(\hat{R}^{k}\right)_{k=1}^{3}\right)$ is an equilibrium, then

1) $\hat{q}_{1} \hat{z}_{1}^{v}+\hat{q}_{2}^{k(v)} \hat{z}_{2}^{v}<\varepsilon$ for $v \in N_{k}, k=2$, (firms with origin in country $h$ do notproduce),

2) $\hat{q}_{2}^{1}=\hat{q}_{2}^{2}=\hat{q}_{2}^{3}$ (factor prices are equalized between the twocountries).

The effects of economic integration as indicated by 1) of Proposition 2 are rather drastical with respect to the distribution of firms, since essentially only country 1 firms are open in the equilibrium. It should of course be remembered that production will be carried out in all countries (since this is the only way of activating the second production factor), so the result does not pertain to production volumes (at least when considered in 
terms of input). Moreover, under constant returns to scale profits are zero also when production is nonzero, so one might wonder whether it matters at all whether production is organized in one country or in several.

Actually, it does matter, even in our simple model. With a small number of firms, output volatility is increased as compared with a situation where there are more firms. This means that overall welfare is lowered if the three countries considered perform an integration of the type considered.

Proposition 3. Assume that $\left|N_{1}\right|>\left|N_{2}\right|=\left|N_{3}\right|$, and that factor endowments are proportional. Then aggregate utility is larger under no integration than under full integration: if

$$
\left(\left(\hat{x}^{h}, \hat{\theta}^{h}\right)_{h=1}^{3},\left(\hat{\mu}_{v},\left(\hat{z}_{h, i}^{v}, \hat{x}_{h, i}^{v}\right)_{(h, i) \in H_{k(v)}}\right)_{v \in N},(\hat{q}, \hat{p}),\left(\hat{R}^{k}\right)_{k=1}^{3}\right)
$$

and

$$
\left(\left(\tilde{x}^{h}, \tilde{\theta}^{h}\right)_{h=1}^{3},\left(\tilde{\mu}_{v},\left(\tilde{z}_{h, i}^{v}, \tilde{x}_{h, i}^{v}\right)_{(h, i) \in H_{k(v)}}\right)_{v \in N},(\tilde{q}, \tilde{p}),\left(\tilde{R}^{k}\right)_{k=1}^{3}\right)
$$

are equilibria with full and with no integration, respectively, then

$$
\mathrm{E}\left[\sum_{h=1}^{3} u_{h}\left(\tilde{x}^{h}\right)+\sum_{v \in N} u_{h}\left(\tilde{x}^{h}\right)\right]>\mathrm{E}\left[\sum_{h=1}^{3} u_{h}\left(\hat{x}^{h}\right)+\sum_{v \in N} u_{v}\left(\hat{x}^{v}\right)\right] .
$$

It might be argued that the instance of welfare inferior economic integration exhibited in our model is artificial, since it is based on the increased volatility of output due to the smaller number of active firms. If the number of firms can be increased within each country, and in particular in the larger country 1 , then these effects may indeed by eliminated. However, the main point of our model is to show that entrepreneurship matters; if conducting a firm is costly in the sense that specific resources of some type are needed for this activity, then it would be possible to exhibit cases where integration of unequally endowed countries would have detrimental effects also on production and consumption. This would however demand an extension of the model beyond the scope of the present paper.

\section{Concluding Comments}

In the model considered in this paper, we have shown that integrating weak and strong partners may lead to a welfare loss, not only to one of these partners but to both of them. This loss occurs as a result of increased riskiness; production will be monopolized by the strong partner and thereby concentrated to fewer units, so that downturns are more directly felt. The reason why this happens-in our model world where all have access to the same technology — is that the entrepreneurs can be distinguished by their origin, so that production in the weaker country is at a disadvantage in questions of obtaining credits.

The precondition for successful integration (where integration is considered as free choice of localization of the firms of the countries involved) is that the partners must not be too unequal, since the economically stronger part - where strength is measured as availability of entrepreneurial skills-will reap the benefits while the weaker part may suffer a loss. On the other hand, integration of the small countries of roughly equal size may be beneficial to all countries, including those not directly involved. This relates to the theory of piecemeal economic reform (Hatta [21], see also Ju and Krishna [22]): several small steps may be better than a single large step.

Clearly, our message is not that economic integration is undesirable. But if the final goal is a fully integrated world economy, where not only limitations to entrepreneurship, but also country differences in obtaining finance, are eliminated, the final goal could be achieved through integrating weak countries with the strong country one by one, or alternatively by integrating the weak countries first and then proceed to the final full integration. Our results indicate that the latter approach should be preferred since it the piecemeal integration of small with stronger countries tend to drain the small countries of business activity and give rise to greater volatility of consumption and welfare.

In a more limited perspective, our model may be seen as a first step towards a theoretical modelling of processes observed in countries becoming economic integrated with regions having a more developed economy. In many cases, the effects of this integration has been the closing down of large sectors of the economy, combined with a transfer of existing more advanced economic activities from these countries to the more developed ones. Such processes are beyond our scope with the present model which in accordance with classical trade 
models assumes equal access to technology, but the explicit formulation of the choice of site and production seems to be a necessary first step towards a better understanding of such phenomena.

\section{References}

[1] Viner, J. (1950) The Customs Unions Issue. Carnegie Endowment for International Peace, New York.

[2] Vanek, J. (1965) General Equilibrium of International Discrimination: The Case of Customs Unions. Harvard University Press, Cambridge, MA.

[3] Gandolfo, G. (2014) International Trade. 3rd Edition, International Trade Theory and Policy, Springer-Verlag, Berlin Heidelberg.

[4] Helpman, E. and Razin, A. (1978) A Theory of International Trade under Uncertainty. Academic Press, New York.

[5] Hoff, K. (1996) A Reexamination of the Neoclassical Trademodel under Uncertainty. Journal of International Economics, 36, 1-27. http://dx.doi.org/10.1016/0022-1996(94)90055-8

[6] Newbery, D.M.G. and Stiglitz, J.E. (1984) Pareto Inferiortrade. Review of Economic Studies, 51, 1-12. http://dx.doi.org/10.2307/2297701

[7] Tille, C. (2005) The Welfare Effect of International Asset Market Integration under Nominal Rigidities. Journal of Intenational Economics, 65, 221-247.

[8] Kemp, M.C. and Wan, H. (1976) An Elementary Proposition Concerning the Formation of Customs Unions. Journal of International Economics, 6, 95-97.

[9] Markusen, J.R. and Venables, A.J. (1998) Multinational Firms and the New Trade Theory. Journal of International Economics, 46, 183-203. http://dx.doi.org/10.1016/S0022-1996(97)00052-4

[10] Markusen, J.R. and Venables, A.J. (2000) The Theory of Endowment, Intra-Industry and Multi-National Trade. Journal of International Economics, 52, 209-234.

[11] Rauch J.R. and Watson, J. (2004) Network Intermediaries in International Trade. Journal of Economics \& Management Strategy, 13, 69-93. http://dx.doi.org/10.1111/j.1430-9134.2004.00004.x

[12] Yu, Z. (2002) Entrepreneurship and Intra-Industry Trade. Weltwirtschaftliches Arkiv, 138, 277-289. http://dx.doi.org/10.1007/BF02707745

[13] Wu, J.P. (2005) Trade Agreements as Self-Protection. Review of International Economics, 13, 472-484. http://dx.doi.org/10.1111/j.1467-9396.2005.00518.x

[14] Amiti, M. (1998) Inter-Industry Trade in Manufactures: Does Country Size Matter? Journal ofInternational Economics, 44, 231-255.

[15] Bond, E.W., Syropoulos, C. and Winters, L.A. (2001) Deepening of Regional Integration and Multilateral Trade Agreements. Journal of International Economics, 53, 335-361. http://dx.doi.org/10.1016/S0022-1996(00)00064-7

[16] Ornelas, E. (2005) Trade Creating Free Trade Areas and the Undermining of Multilateralism. European Economic Review, 49, 1717-1735. http://dx.doi.org/10.1016/j.euroecorev.2004.03.010

[17] Abrego, L., Riezman, R. and Whalley, J. (2006) How Often Are Propositions on the Effects of Regional Trade Agreements Theoretical Curiosa? Journal of International Economics, 68, 59-78. http://dx.doi.org/10.1016/j.jinteco.2005.03.003

[18] Chipman, J.S. (1974) Homothetic Preferences and Aggregation. Journal of Economic Theory, 8, 26-38. http://dx.doi.org/10.1016/0022-0531(74)90003-9

[19] Leland, H.E. and Pyle, D.H. (1977) Informational Asymmetries, Financial Structure and Financial Intermediation. The Journalof Finance, 32, 371-387. http://dx.doi.org/10.2307/2326770

[20] Diamond, D. (1984) Financial Intermediation and Delegated Monitoring. Review of Economic Studies, 51, 393-414. http://dx.doi.org/10.2307/2297430

[21] Hatta, T. (1977) A Theory of Piecemeal Policy Recommendations. The Review of Economic Studies, 44, 1-21. http://dx.doi.org/10.2307/2296969

[22] Ju, J. and Krishna, K. (2005) Welfare and Market Access Effect of Piecemeal Tariff Reform. Journal of International Economics, 51, 305-316. http://dx.doi.org/10.1016/S0022-1996(99)00024-0

[23] Gale, D. and Mas-Colell, A. (1975) An Equilibrium Existence Theorem for a General Model without Ordered Preferences. Journal of Mathematical Economics, 2, 9-15. 


\section{Appendix: Proofs of Propositions}

The present section contains the proofs of the propositions stated in the text.

Proof of Proposition 1: The proof of existence follows the standard approach, defining suitable improvement correspondences for each agent and for each of the proces and repayment rates, and using a fixed point theorem to show that there is an allocation together with prices and repayment rates such that no improvement is possible.

For each factor owner $h$, let $X_{h}=\left(\mathfrak{R}_{+}^{2}\right)^{S}$, and let $\Theta=\left\{\left(\theta_{1}, \theta_{2}, \theta_{3}\right) \in \mathfrak{R}_{+}^{3} \mid \sum_{k=1}^{3} \theta_{k}=1\right\}$; elements of $X_{h}$ are statedependent consumption bundles $x^{h}$, and $\theta^{h} \in \Theta$ denotes the vector of shares of savings used for buying bonds of each type. For entrepreneurs $v \in N$, let $X_{v}=\mathfrak{R}_{+}^{4} \times\left(\mathfrak{R}_{+}^{2}\right)^{S}$. By the assumption (c), there are convex and compact subsets $\bar{X}_{h}, h=1,2,3$, and $\bar{X}_{v}, v \in N$, such that for all allocations $\left(x^{h}\right)_{h=1}^{3},\left(\left(z_{h, i}^{v}, x_{h, i}^{v}\right)_{(h, i) \in H_{k(v)}}\right)_{v \in N}$ which are feasible (in the sense of satisfying 3) of Definition 1), we have that $x^{h} \in \operatorname{int} \bar{X}_{h}, h=1,2,3$, $\left(z_{h, i}^{v}, x_{h, i}^{v}\right) \in$ int $\bar{X}_{v}$ for each $v \in N$.

Let $\Delta_{0}$ be the space of factor prices $q$, normalized so that $\sum_{i=1}^{2} \sum_{h=1}^{3} q_{i}^{h}=1$, and similarly, let $\Delta_{1}$ be the set of normalized state-dependent prices of consumptions goods. For each $(h, i)$, let $R^{h}>\frac{\partial f_{i}}{\partial z_{j}}(0), i, j=1,2$, and let $\Lambda=\prod_{h=1}^{3}\left[0, \bar{R}^{h}\right]$ be the set of feasible nominal repayment rates. For each factor owner $h$, let $\gamma_{h}: \Delta_{0} \times \Delta_{1} \times \Lambda \rightarrow X_{h} \times \Theta$ be the budget correspondence given by

$$
\gamma_{h}(q, p, R)=\left\{\left(z^{h}, x^{h}, \theta^{h}\right) \in \bar{X}_{h} \mid p_{1}(s) x_{1}^{h}(s)+p_{2}(s) x_{2}^{h}(s) \leq\left[q_{1} \omega_{1}^{h}+q_{2} \omega_{2}^{h}\right] \sum_{h=1}^{3} \theta_{k}^{h} \pi(s) R^{k}, s \in S\right\}
$$

Then $\gamma_{h}$ has nonempty, compact and convex values and is continous (upper and lower hemicontinuous). Further let $\xi_{h}: \Delta_{0} \times \Delta_{1} \times \Lambda \rightarrow \bar{X}_{h}$ be the demand correspondence defined by

$$
\xi_{h}((q, p), R)=\left\{\left(\hat{z}^{h}, \hat{x}^{h}\right) \in \gamma_{h}((q, p), R) \mid \operatorname{E} u_{h}\left(\hat{x}^{h}\right) \geq \operatorname{E} u\left(\hat{x}^{h}\right), \operatorname{all}\left(z^{h}, x^{h}\right) \in \gamma_{h}((q, p), R)\right\}
$$

By our assumptions on utility functions, $\xi_{h}$ is upper hemicontinuous with closed and convex values.

For each entrepreneur $v \in N$, define the budget correspondence $\gamma_{v}: \Delta_{0} \times \Delta_{1} \times \Lambda \rightarrow X_{v}$ by

$$
\begin{aligned}
\gamma_{v}(q, p, R)= & \left\{\left(z^{v}, x^{v}\right) \in \bar{X}_{v} \mid \exists(h, i) \in H_{k(v)}, z_{i, h}^{v} \in \mathbb{R}_{+}^{2}: p(s) \cdot x_{h, i}^{v}(s)\right. \\
& \left.\leq \max \left\{0, p_{i}(s) f_{i}\left(z_{h, i}^{v}\right)-R^{k}\left(q_{1} z_{h, i, 1}^{v}+q_{2}^{h} z_{h, i, 2}^{v}\right)\right\}, \text { all } s \in S\right\},
\end{aligned}
$$

and define the demand correspondence $\xi_{v}: \Delta_{0} \times \Delta_{1} \times \Lambda \rightarrow \bar{X}_{v}$ by

$$
\xi_{v}(q, p, R)=\left\{\hat{x}^{v} \in \gamma_{v}(p, q, R) \mid \mathrm{Eu}_{v}\left(\hat{x}^{v}\right) \geq \mathrm{Eu}_{v}\left(x^{v}\right) \text {, all } x^{v} \in \gamma_{v}((q, p), R)\right\} .
$$

Then $\xi_{v}$ is upper hemicontinuous with compact values, but $\xi_{v}((q, p), R)$ is not necessarily convex (since there may be several utility maximizing choices corresponding to different $(h, i)$ combinations). We therefore define $\operatorname{conv} \xi_{v}: \Delta_{0} \times \Delta_{1} \times \Lambda \rightarrow \bar{X}_{v}$ by

$$
\operatorname{conv} \xi_{v}((q, p), R)=\operatorname{conv}\left(\left\{x^{v} \mid x^{v} \in \xi_{v}((q, p), R)\right\}\right)
$$

(the set of all convex combinations of points in $\left.\xi_{v}((q, p), R)\right)$. Clearly, conv $\xi_{v}$ is upper hemicontinuous with nonempty, convex and compact values.

Let $X=\prod_{h=1}^{3}\left[\bar{X}_{h} \times \Theta\right] \times \prod_{v \in N} \bar{X}_{v} \times \Delta_{0} \times \Delta_{0} \times \Lambda$. Define the correspondence $\varphi_{0}: X \rightarrow \Delta_{0}$ by

$$
\varphi_{0}\left(\left(x^{h}, \theta^{h}\right)_{h=1}^{3},\left(z^{v}, x^{v}\right)_{v \in N}, q, p, R\right)=\left\{q^{\prime} \in \Delta_{0} \mid \sum_{v \in N} q^{\prime} \cdot z^{v}>\sum_{i=1}^{3} q^{\prime} \cdot z^{h}\right\},
$$

let $\varphi_{1}: X \rightarrow \Delta_{1}$ be given by

$$
\varphi_{1}\left(\left(x^{h}, \theta^{h}\right)_{h=1}^{3},\left(z^{v}, x^{v}\right)_{v \in N}, q, p, R\right)=\left\{q^{\prime} \in \Delta_{1} \mid p^{\prime} \cdot\left(\sum_{h=1}^{3} x^{h}+\sum_{v \in N} x^{v}\right)>\sum_{s \in S} \sum_{v \in N} \tau^{v}(s) p^{\prime} \cdot f\left(z^{v}\right)\right\},
$$


and finally, define $\varphi_{2}: X \rightarrow \Lambda$ by

$$
\varphi_{2}\left(\left(x^{h}, \theta^{h}\right)_{h=1}^{3},\left(z^{v}, x^{v}\right)_{v \in N}, q, p, R\right)=\left\{R^{\prime} \in \mathcal{R} \mid\left(\sum_{h=1}^{3}\left(R^{\prime}\right)^{h}+\sum_{h=1}^{3}\left(q \cdot \omega^{h}\right) \theta_{k}^{h}\right)>\sum_{h=1}^{3} R^{k} \sum_{h=1}^{3}\left(q \cdot \omega^{h}\right) \theta_{k}^{h}\right\} .
$$

The three correspondences $\varphi_{0}, \varphi_{1}, \varphi_{2}$ have open graph and convex values, and they satisfy the following irreflexivity condition: If $\left(\left(x^{h}, \theta^{h}\right)_{h=1}^{3},\left(z^{v}, x^{v}\right)_{v \in N}, q, p, R\right) \in X$ is such that

$$
\begin{aligned}
& \left(x^{h}, \theta^{h}\right) \in \xi_{h}(p, q, R), h=1,2,3, \\
& \left(z^{v}, x^{v}\right) \in \xi_{v}(p, q, R) \text { all } v \in N,
\end{aligned}
$$

then $(q, p, R) \notin\left(\varphi_{0} \times \varphi_{1} \times \varphi_{2}\right)\left(\left(x^{h}\right)_{h=1}^{3},\left(\left(z_{h, i}^{v}, x_{h, i}^{v}\right)_{(h, i) \in H_{k(v)}}\right)\right)_{v \in N}$. Applying a fixed-point theorem for correspondences (Gale and Mas-Colell [23]), we get that there is $x=\left(\left(x^{h}, \theta^{h}\right)_{h=1}^{3},\left(z^{v}, x^{v}\right)_{v \in N}, q, p, R\right)$ such that (7) holds and $\varphi_{i}(x)=\varnothing$ for $i=0,1,2$. By our construction, this means that the feasibility constraints 3)-4) of Definition 1 hold for $\left(\left(x^{h}, \theta^{h}\right)_{h=1}^{3},\left(z^{v}, x^{v}\right)_{v \in N}, q, p, R\right)$, which therefore is an equilibrium.

Proof of Proposition 2: It is convenient to begin with part 2): Since only one factor is not traded, the price of the remaining factor is the same in the three countries. If the active entrepreneurs choose country and industry of operation so that expected profits are maximal, then the factor input combination in each industry is proportional between countries, and therefore, factor prices must be equal in the three countries, $\hat{q}_{2}^{1}=\hat{q}_{2}^{2}=\hat{q}_{2}^{3}=\hat{q}_{2}$.

1) Due to constant returns to scale, expected profits

$$
\operatorname{Emax}\left\{0, \tau_{v} f_{i}\left(z_{h, i}^{v}\right)-R^{k}\left(q_{1} z_{h, i, 1}^{v}+q_{2}^{h} z_{h, i, 2}^{v}\right)\right\}
$$

must be 0 for all active entrepreneurs, so that the nominal repayment rates satisfy $R^{1}=R^{2}=R^{3}=R$. Since the country bonds have the same nominal repayment, the factor owners will prefer country 1 bonds, which by the law of large numbers approach a risk-free bond with nominal repayment equal to the expected value of all the country bonds, which is $\pi R$, where $\pi$ is the probability of the random output shock. Consequently, the share bonds of country 2 and 3 in the savings portfolio of factor owners will approach zero, and since production of the entrepreneurs of these countries are financed by the bonds, their input is reduced correspondingly so as to become arbitrarily small.

Proof of Proposition 3: Under the conditions of no integration, entrepreneurs of country $h$ can operate only in country $h$, but by proportionality of resources, the same input combinations will be achieved under integration. Moreover, there will be either more active entrepreneurs, or the production of will be more evenly spread among entrepreneurs, under no integration than in the integrated equilibrium. By the assumption of risk averse consumers, this gives the conclusion of the proposition. 


\section{Submit or recommend next manuscript to SCIRP and we will provide best service for you:}

Accepting pre-submission inquiries through Email, Facebook, LinkedIn, Twitter, etc.

A wide selection of journals (inclusive of 9 subjects, more than 200 journals)

Providing 24-hour high-quality service

User-friendly online submission system

Fair and swift peer-review system

Efficient typesetting and proofreading procedure

Display of the result of downloads and visits, as well as the number of cited articles

Maximum dissemination of your research work

Submit your manuscript at: http://papersubmission.scirp.org/ 